\title{
Política pública socioassistencial e o ensino de música para crianças e adolescentes
}

\author{
Andersonn Henrique Araújo (Universidade Estadual do Rio Grande do Norte, Natal, Brasil) \\ andersonn.henrique.araujo@gmail.com
}

\begin{abstract}
Resumo: Este ensaio aborda o ensino de música em ambientes socioassistenciais na política pública brasileira. Objetiva-se discutir os aspectos referentes ao Serviço de Convivência e Fortalecimento de Vínculos, inter-relacionando a área da Educação Musical para compreender que conexões que existem entre o ensino de música e a macropolítica assistencial. Utilizou-se como metodologia o cruzamento entre os documentos oficiais, referências nas áreas de Educação Musical e Serviço Social. Empregou-se a interpretação dos documentos oficiais a partir da triangulação de referenciais. Como resultado, foi possível constatar que a partir da apropriação da legislação vigente, o trabalho social demanda para o educador musical desafios como o trabalho intersetorial, pois é marcado pela superação de vulnerabilidade social através da música.

Palavras-chave: Educação musical e práticas socioassistenciais; Projetos sociais; Ensino de música na Política Pública de Assistência Social.
\end{abstract}

Public social assistance policy and teaching of music for children and teenagers

Abstract: This essay deals with the teaching of music in socioassistential environments in Brazilian public policy. The objective is to discuss the aspects related to the Serviço de Convivência e Fortalecimento de Vínculos, interrelating the area of Music Education to understand the connections that exist between the teaching of music and the macro politics of social care. The cross-reference between the official documents and references in the areas of Music Education and Social Work was used as methodology. The interpretation of the official documents was used from the triangulation of references. As a result, it was possible to verify that from the appropriation of the current legislation, social work demands for the musical educator challenges such as intersectoral work, since it is marked by the overcoming of social vulnerability through music.

Keywords: Music education and social assistance practices; Social projects; Music education in Public Policy for Social Assistance.

\section{Introdução}

Nas últimas três décadas no Brasil, multiplicaram-se os espaços assistenciais que utilizam da arte como mecanismo promotor de respostas sociais. Houve o crescimento do número de oficinas de música em hospitais, organizações não governamentais (ONG), creches, hotéis, grupos livres de estudo, associações comunitárias, casas de passagem ${ }^{1}$, abrigos $^{2}$, centros sociais vinculados a igrejas, associações empresariais, entre outros.

Em parte, isso ocorreu devido a conscientização da importância da aprendizagem musical como garantia de direitos e de desenvolvimento humano preconizado nas leis brasileiras, como o Estatuto da Criança e do Adolescente (BRASIL, 1990). Essa conscientização é um processo dinâmico e não linear, no qual os interesses sociais se manifestam através de associações e instituições científico-educacionais que ora são convidadas para participarem, fomentarem e retroalimentarem as políticas públicas e ora criam tensões quando os interesses governamentais divergem dos interesses da sociedade.

Outra vertente que auxilia na utilização da música como intervenção social da política pública é o seu reconhecimento como área científica e que ao mesmo tempo é um bem cultural a que o cidadão deve ter acesso. Como exemplo, o caderno de Orientações Técnicas sobre o Serviço de Convivência e Fortalecimento de Vínculos para Crianças e Adolescentes de 6 a 15 anos traz o ensino de música como auxiliadora do desenvolvimento cognitivo (BRASIL, 2010).

Esse processo histórico não linear e dialógico é construído a partir da dinâmica social que são emergentes das relações sociais que muitas vezes entram em conflito com o 
próprio poder público. Fatores sociais, econômicos, religiosos, políticos etc. ajudam a compor a força motriz dos processos que impulsionam demandas que impactam na política pública assistencial brasileira (SARTORI, 2012). Dentro deste contexto, às vezes conflituoso, surge a Política Nacional de Assistência Social (BRASIL, 2004).

Dentre as ações da Política Nacional de Assistência Social (PNAS) que utilizam música, podemos destacar o Serviço de Convivência e Fortalecimento de Vínculos para Crianças e Adolescentes de 06 a 15 anos (SCFV).

O SCFV pode ser oferecido em escolas, ONG, núcleos de atendimento, Centros de Referência da Assistência Social - CRAS, casas de passagem e desde 2010, incorporou as ações do Programa de Erradicação do Trabalho Infantil.

Em minha atuação como educador musical nesses contextos percebi que pouco tem se discutido sobre a Política Pública Assistencial e suas influências na atuação do monitor/ facilitador de Música. Apesar de se tratarem de políticas e ações que são regidas por uma legislação específica, os trabalhos da Educação Musical sobre ONG, programas, projetos sociais governamentais ou até mesmo sobre o Programa de Erradicação do Trabalho Infantil, não têm abordado o tema.

Como exemplo, o livro organizado por Jusamara Souza (2014) que traz discussões sobre o ensino-aprendizagem a partir da ótica da sociologia da música nesses espaços. Apesar de refletir sobre as relações formativas dos sujeitos que estão presentes no processo educativo, o livro não contempla a legislação que permeia os ambientes socioassistenciais nem discute sistematicamente a política pública. Se por um lado temos trabalhos sob as mais diversas óticas que abordam a legislação e a prática do professor de música na sala de aula das escolas de educação básica (PENNA, 2008, 2012), por outro, temos, como área, deixado de lado a discussão sobre a legislação no âmbito do trabalho social com música.

Dentre outras, podemos elencar duas causas para esta ausência: $1^{\mathrm{a}}$. O envolvimento da área com a Lei 11.769/2008, na qual a Associação Brasileira de Educação Musical teve um papel fundamental na articulação da aprovação. Apesar de o espaço não escolar ser um campo de trabalho do licenciado em música, o sentimento de pertencimento da área em relação à Lei 11.769/2008 é maior do que com a Política Nacional de Assistência Social. 2a . Os cursos de formação de professores geralmente focam seus campos de atuação para a docência na escola básica. A exemplo a UERN e a UFRN que possuem componentes curriculares para preparação de professores para os espaços não escolares. Todavia, na carga horária de estágio, a escola básica em seus diferentes níveis é privilegiada em detrimento do estágio em espaços socioassistenciais. É importante salientar que a maior demanda de formação de profissionais é para a atuação na educação básica, além disso, a Resolução $n^{0} 2$, de 1 de julho de 2015, define as diretrizes curriculares nacionais para a formação inicial em nível superior e afirma que o principal campo de formação nas licenciaturas é a educação básica.

É necessário que a Educação Musical problematize, se aproprie e produza conhecimentos que permeiam as oficinas de música nesses espaços. Para que como área do conhecimento, possa ela mesma pensar a práxis educativa conectada com a legislação vigente e com a dinâmica social, propor novas formas de relação do ensino de música e problematizar a formação necessária para os profissionais que atuam em espaços socioassistenciais.

\section{Política Pública Socioassistencial brasileira para crianças e adolescentes}

Desde a década de 1990 há pressões externas para que o Brasil implemente políticas na área social. Nessa época, o país era dependente de órgãos financiadores como o Banco Mundial e o Banco Interamericano de Desenvolvimento. Tais órgãos elaboram 
metas através de documentos com orientações estratégicas para os países tomadores de empréstimos, bem como cláusulas específicas que sugestionam maiores investimentos na educação básica. Esse é um dos motivos para que a maior parte das políticas sociais atenda a crianças e adolescentes de 5 a 15 anos, pois é a faixa etária com maior demanda do ensino fundamental (BUFALO, 2008; CANDIDO, 2005).

Tais intervenções fizeram com que o Brasil implementasse uma Política Assistencial descentralizada e não assistencialista, um advento recente ${ }^{3}$ de contornos delineados a partir da Constituição de1988 (SARTORI, 2012).

Em 22 de setembro de 2004 foi aprovada a Política Nacional de Assistência Social (PNAS). Tal política rege-se sobre os seguintes princípios:

I- Supremacia do atendimento às necessidades sociais sobre as exigências de rentabilidade econômica;

II- Universalização dos direitos sociais, a fim de tornar o destinatário da ação assistencial alcançável pelas demais políticas públicas;

III- Respeito à dignidade do cidadão, à sua autonomia e ao seu direito a benefícios e serviços de qualidade, bem como à convivência familiar e comunitária, vedando-se qualquer comprovação vexatória de necessidade;

IV- Igualdade de direitos no acesso ao atendimento, sem discriminação de qualquer natureza, garantindo equivalência às populações urbanas e rurais;

V- Divulgação ampla dos benefícios, serviços, programas e projetos assistenciais, bem como os recursos oferecidos pelo Poder Público e dos critérios de sua concessão (BRASIL, 2004, p. 33).

É interessante destacar no texto acima que a intersetorialidade é dos pontos cruciais na PNAS. Intenciona-se trabalhar com as famílias de diversas maneiras, objetivando resgatar e resguardar o direito ao desenvolvimento humano. As oficinas de música acontecem com usuário ${ }^{4}$ do serviço e sua família através de ações transversais junto à área da saúde, direitos humanos etc. Tais ações podem ser promovidas tanto pelos órgãos gestores quanto pelos facilitadores que atuam com música e isso pode se tornar um desafio para nós, educadores.

Ao discutir a intersetorialidade, Nascimento (2010) afirma que há contornos definidos nas ações das políticas públicas. Concordamos com a autora que define que o primeiro contorno é uma dimensão territorial das macropolíticas, pois promovem ações que atingem uma mesma população no mesmo território. Assim, o atendimento aos usuários dos serviços assistenciais deve convergir para o mesmo foco de ação. No caso do ensino de música no SCFV, a superação do risco e da vulnerabilidade social.

Para Nascimento (2010), trabalhar em rede significa também assumir que as ações setoriais, com abrangência mais pontual, não conseguem suprir a demanda assistencial. E como estratégia desta rede colaborativa, o planejamento, a execução e o controle na prestação dos serviços devem garantir o acesso igual aos direitos e deveres constitucionais. Neste sentido, o acesso ao ensino de música se torna um direito constitucional inserido numa rede colaborativa de ações intersetoriais.

Há um segundo contorno que retroalimenta a macropolítica ao passo que é uma de suas retroalimentadoras e acontece no âmbito do cotidiano das ações: A prática intersetorial promove a convivência entre profissionais de diversas áreas do conhecimento favorece uma ação convergente e de ampla influência. A troca de experiências e saberes que são aprendidos nas ações setoriais influenciam em como o aluno aprende música nos projetos sociais, ao passo que também influencia nos conteúdos e metodologias que o professor emprega em sua oficina de música gerando um ponto de intersecção entre ações, metodologias e conhecimentos musicais na busca pela superação da vulnerabi- 
lidade social. O cruzamento entre macropolíticas-macropolíticas, ações setoriais-ações setoriais e macropolíticas-ações setoriais é um ponto crucial da ação do educador musical no Serviço de Convivência e Fortalecimento de Vínculos (SCFV).

Se a articulação entre as macropolíticas que compõe a seguridade social se torna um macrodesafio, a articulação entre as ações destas políticas também se constitui uma ação problematizadora e que interfere na ação do educador de música nesses espaços. Segundo Nascimento (2010, p. 96), “A incorporação da intersetorialidade nas políticas públicas trouxe a articulação de saberes técnicos, já que os especialistas em determinada área passaram a integrar agendas coletivas e compartilhar objetivos comuns".

A afirmativa de Nascimento (2010), interpretada dentro da ótica da educação musical, se concretiza no cotidiano do educador que possui uma rede de macropolíticas públicas, ao passo em que convive com diversos profissionais que trabalham no SCFV e em outros espaços de convivência como escolas, unidades de saúde etc. Como exemplo disso, é comum encontrarmos crianças e adolescentes que participam do SCFV e também do Programa Mais Educação nas escolas. Nos dois momentos é possível aprender a música, apesar de cada ação possuir um objetivo diferente e acontecer dentro de políticas distintas: o Mais Educação como política setorial gerenciada pelo sistema educativo e o SCFV como serviço contínuo gerenciado pela assistência social.

Logo, as práticas intersetoriais são ações da macropolítica e ao mesmo tempo uma prática nas oficinas. Neste sentido, é necessário que o monitor/facilitador de música busque colaboradores dentre as instituições parceiras do trabalho social. As parcerias são inerentes ao cotidiano pedagógico e conhecer as potencialidades da comunidade no qual o SCFV está inserido é um passo para se construir e fortalecer essa rede de atuação.

O sistema educacional é integrado à rede do SCFV. Existe uma relação institucional entre educação e assistência social, para que o usuário tenha direito ao benefício do Bolsa Família, é necessário ter frequência escolar e no Serviço de Convivência e Fortalecimento de Vínculos superior a 75\%. Há outra relação no âmbito dos conhecimentos que as crianças vivenciam.

Em pesquisa de mestrado (ARAUJO, 2015) que objetivou estudar as relações que existem entre o ensino de música e a cultura em um núcleo do SCFV em Natal/RN, constatei que a rede socioassistencial não se constitui apenas na busca por um princípio interativo, mas está presente na vida das crianças e adolescentes que participavam do SCFV estudado. A intersetorialidade no trabalho social implica também em relações do conhecimento. Ao observar as oficinas de violão, os usuários conseguiam identificar os ritmos musicais que a monitora de música havia proposto como forma de apreciação/ execução. Quando questionado se os aprendizes haviam ouvido ou estudado aqueles ritmos, eles afirmavam que o professor da banda de fanfarra do Programa Mais Educação da escola em que eles frequentavam havia ensinado os ritmos. As experiências escolares se fazem presentes na oficina de música no serviço socioassistencial. Para as crianças e adolescentes usuárias do Serviço, a escola é a instituição mais próxima do SCFV e cabe aos educadores musicais que trabalham elaborar estratégias que potencializam esse diálogo de experiências musicais.

Há outro desdobramento da intersetorialidade: se há o enfraquecimento da rede socioassistencial, também há o enfraquecimento do Serviço de Convivência e Fortalecimento de Vínculos. Contudo, Maciel (2011) ao estudar a educação musical nos projetos sociais, afirma que as ONG surgem porque há o enfraquecimento das ações do poder público. Entretanto, temos uma posição que agrega outro olhar a essa concepção, aparen- 
temente dicotômico, mas que é complementar.

Atualmente, as ações socioassistenciais, governamentais ou não governamentais, não surgem para suprir um suposto enfraquecimento do poder público e sim para fortalecer a rede socioassistencial de uma determinada localidade. As ONG são fiscalizadas e orientadas pelo poder público. Assim, se faltam ações públicas/fiscalizatórias, pessoas mal-intencionadas podem se aproveitar de tal fato para desviar o objetivo social.

Entretanto, é comum o discurso na literatura na área de Educação Musical (FUCCI AMATO, 2009; SANTOS, 2005) de que as ONG ou projetos sociais que trabalham com música surgem como uma tentativa governamental "para minimizar o efeito devastador causado pela grande lacuna no ensino de música na educação básica” (FUCCI AMATO, 2009, p. 92).

Santos (2005), ao constatar que as escolas de ensino fundamental geralmente não possuíam a disciplina de Música, afirma que o governo começa a apoiar projetos sociais para acautelar-se da responsabilidade de oferecê-la. Segundo o autor, verbas mais restritas são destinadas para uma política compensatória devido ao descaso com o ensino público.

Na atualidade, pensar nas práticas socioassistenciais que acontecem nas ONG e/ ou promovidas pelo governo como uma compensação é desprezar o principal papel dessas instituições que, geralmente, não estão diretamente vinculadas ao ensino e aprendizagem, mas sim à superação da vulnerabilidade social, sem desprezar o compromisso de uma educação musical de qualidade.

Outro ponto que discordamos em relação à análise presente nos trabalhos de Fucci Amato (2009) e no de Santos (2005) é o fato de interligarem a atuação da Política Educacional à Política de Assistência Social. Esse posicionamento pode não reconhecer a relativa interdependência das duas esferas públicas. Nessa perspectiva, pode-se ter a impressão errônea de que o sistema assistencial é uma muleta do educacional, como se as duas políticas tivessem o mesmo objetivo. Ou como se a política educacional fosse a principal política estatal, e promovesse lacunas pela sua pouca eficiência, para suprir tais lacunas seriam necessárias ações compensatórias socioassistenciais. Entretanto, os sistemas educacionais e socioassistenciais são bem delimitados e cada um responde a uma legislação, a objetivos e a propósitos distintos.

Há três problemas principais na perspectiva de tratar a ação assistencial como ação compensatória: o primeiro está vinculado à subestimação da capacidade educacional e transformadora desses espaços; o segundo é que a Educação e a Assistência Social são deveres inerentes e constitucionais do Estado brasileiro, assim, se um setor está atuando com o objetivo principal de compensar as ações do outro, há uma ação que contradiz a Carta Magna brasileira; e o terceiro problema inerente à visão compensatória das ações socioassistenciais refere-se à legitimação desses ambientes que possuem um objetivo delineado, trabalhando com aspectos diferentes dos outros espaços educacionais.

Sobre o problema em relacionar as ações socioassistenciais musicais como compensatórias: contextualizar os ensinos em ambientes socioassistenciais com um olhar do sistema educacional é subaproveitar o viés de transformação social direta que a música possui nesses ambientes. Cada política deve ser entendida com um olhar em suas ações, perspectivas, objetivos e concepções. A educação básica atende a uma demanda universalista, promovendo o acesso ao conhecimento humanístico. Tal perspectiva difere das práticas socioassistenciais governamentais que propõe o a superação do risco e da vulnerabilidade social, como podemos observar nas diretrizes presentes na Política Nacional de Assistência Social (BRASIL, 2004). 
Ao pesquisar crianças e adolescentes internos da FEBEM e que participam do Projeto Guri, por exemplo, Hikiji (2006) expõe como a música tem um papel singular de combate ao risco social, transformando pessoas estigmatizadas em sujeitos de direitos aberto a possibilidades. Tais direitos referem-se ao acesso à música, ao lazer, à ampliação de conhecimentos, havendo também a possibilidade dos aprendizes/internos atuarem como instrumentistas. A música para as crianças e adolescentes em cumprimento de medidas socioeducativas em regime fechado tem um papel tão transformador que

As saídas [para as apresentações e concertos externos à FEBEM] eram esperadas ansiosamente. O sentido só podia ser encontrado uma vez inserido o evento no contexto do cotidiano dos internos. A lembrança dos minutos de palco deve ser contraposta às horas do pátio, espaço do tempo que não passa. No palco, colocam-se em prática os mecanismos sensíveis específicos à prática musical, como concentração, tensão, alívio, catarse. Educação também é sentimental (HIKIJI, 2006, p. 179, grifo nosso).

Também são comuns alguns autores se referirem a projetos socioassistenciais como socioculturais, ou como socioeducacionais, como é o caso de Fucci Amato (2009). Entretanto, cada esfera - assistencial, cultural ou educacional - possui uma legislação, operacionalização e concepção específica. Não obstante, quase sempre os projetos socioassistenciais possuem características educacionais e/ou culturais, contudo a legislação vigente para cada espaço é própria. ${ }^{5}$

Sobre o problema em relacionar as ações socioassistenciais como compensatórias, é importante ressaltar que o Estado brasileiro deve garantir os direitos primários dos cidadãos, como o ensino gratuito para todos. Tais direitos estão presentes na Constituição Brasileira de 1988, localizados entre o $5^{\circ}$ ao $17^{\circ}$ artigo (BRASIL, 1988). Quando o Estado não oferta a garantia desses direitos e a sociedade civil ou ONG fazem o papel que é inerente ao Estado, há uma omissão compensatória que é inconstitucional. Constitucionalmente, nem as ONG devem cumprir o papel do Estado na garantia dos direitos básicos, nem os serviços socioassistenciais devem surgir como ações compensatórias das práticas educativas escolares.

Por último, o terceiro problema está relacionado à legitimação da concepção desses ambientes. Gohn (2009), ao tratar das concepções dos projetos sociais de inclusão social, afirma que as ações desses espaços envolvem aprendizagens subjetivas, emocionais e cognitivas acrescidas à aquisição de habilidades sociais, corporais, técnicas, manuais.

Acrescentamos que, além das aprendizagens e aquisição de habilidades, os aprendizes e o facilitador de música atentam para a demanda da superação dos riscos e vulnerabilidades sociais através da convivência. Pois, é nesse foco que surgem os serviços socioassistenciais, tendo a música como caminho e/ou ferramenta de tais ações.

A intervenção socioeducativa

não deve ser vista em hipótese alguma como algum tipo de proposta contra ou alternativa à educação formal, escolar. Ela não deve ser definida pelo que não é, mas sim pelo que ela é - um espaço concreto de formação com a aprendizagem de saberes para a vida em coletivos (GOHN, 2009, p. 32).

Os espaços socioassistenciais governamentais não substituem e nem devem substituir outros espaços de aprendizagem musical, como a escola, conservatório, manifestações da cultura popular, por exemplo. Igualmente, tais espaços não devem servir de ocupação do tempo extraescolar tornando-se coadjuvante do sistema educacional. 


\section{O SCFV}

O Programa de Erradicação do Trabalho Infantil - PETI - objetiva assegurar o desenvolvimento da criança e do adolescente na prevenção e na superação de situações de trabalho infantil. Tal programa vem se alterando desde a sua origem, atualmente ele ocorre dentro do Serviço de Convivência e Fortalecimento de Vínculos para crianças e adolescentes de 6 a 15 anos. O SCFV abarca crianças provindas de diferentes realidades, além do trabalho infanto-juvenil, como crianças que foram exploradas sexualmente, ou em cumprimento de medidas socioeducativas. Portanto, em comum, os usuários dos serviços socioassistenciais apresentam alguma necessidade de intervenção social.

Tais situações envolvem desde separações familiares traumáticas, trabalho infantil, exploração sexual, cumprimento de medidas socioeducativas, pessoas que perderam suas moradias por causa de acidentes etc. Logo, as oficinas de música do Serviço de Convivência e Fortalecimento de Vínculos são destinadas as famílias que estejam passando por dificuldades, independentemente da classe social ou renda familiar. A composição do perfil dos aprendizes de música das políticas públicas socioassistenciais é um misto de homogeneidade da renda familiar, e também da heterogeneidade de situações de risco e vulnerabilidade.

Ao realizar uma pesquisa no SCFV, em Natal/RN, que ocorre no Oratório Dom Bosco, constatei que os usuários são pessoas que possuem pouco acesso a bens materiais e a políticas públicas (ARAUJO, 2015). Uma das explicações para isso acontecer está no fato de que as famílias mais abastadas preferem pagar pelos serviços de auxílio social, como psicólogos e terapias de grupos familiares (SARTORI, 2012).

Há duas influências dessas situações de risco e vulnerabilidade nas oficinas de música no Serviço de Convivência e Fortalecimento de Vínculos: a primeira está no fato de que muitos dos usuários da política pública socioassistencial são retirados do trabalho infantil, ou seja, participam do PETI. E a segunda influência relaciona-se à principal causa de evasão, as crianças e adolescentes abandonam as oficinas de música para voltar a trabalhar. Isso ocasiona uma descontinuidade das ações pedagógico-musicais, ao mesmo tempo em que demanda do profissional de música metodologias que abarquem diferentes níveis de conhecimento. $\mathrm{O}$ cotidiano das crianças e adolescentes que vivem em situação de vulnerabilidade social é permeado ideologicamente pelo trabalho como sustento familiar e único modo de sobreviver.

Nascimento (2014) também traz essas questões ao afirmar que os jovens participantes de um projeto social no bairro do Cabula, em Salvador, alegaram não poderem mais participar das atividades musicais, pois precisavam trabalhar.

Esses jovens, em sua totalidade, declararam que sobreviviam de pequenos ganhos, frutos de eventuais trabalhos que realizavam por ocasião dos festejos populares da cidade ao longo do ano, ou mesmo no comércio das respectivas comunidades. Ao final, constatou-se que, dos 32 alunos que frequentavam as aulas de música, apenas dois ainda compareciam regularmente à escola, enquanto os outros 30, embora estivessem em idade escolar, desistiram dos estudos sem terem concluído suas respectivas formações. O motivo alegado para o abandono escolar era que a escola não lhes ensinava o que necessitavam para conseguir emprego ou ascender socialmente (NASCIMENTO, 2014, p. 115).

Ao pesquisarmos as aprendizagens que ocorriam no SCFV em Parnamirim/RN (ARAUJO, 2009), foi possível constatar que as principais atividades de risco dos ingressantes no referido serviço se davam através do trabalho infantil. 


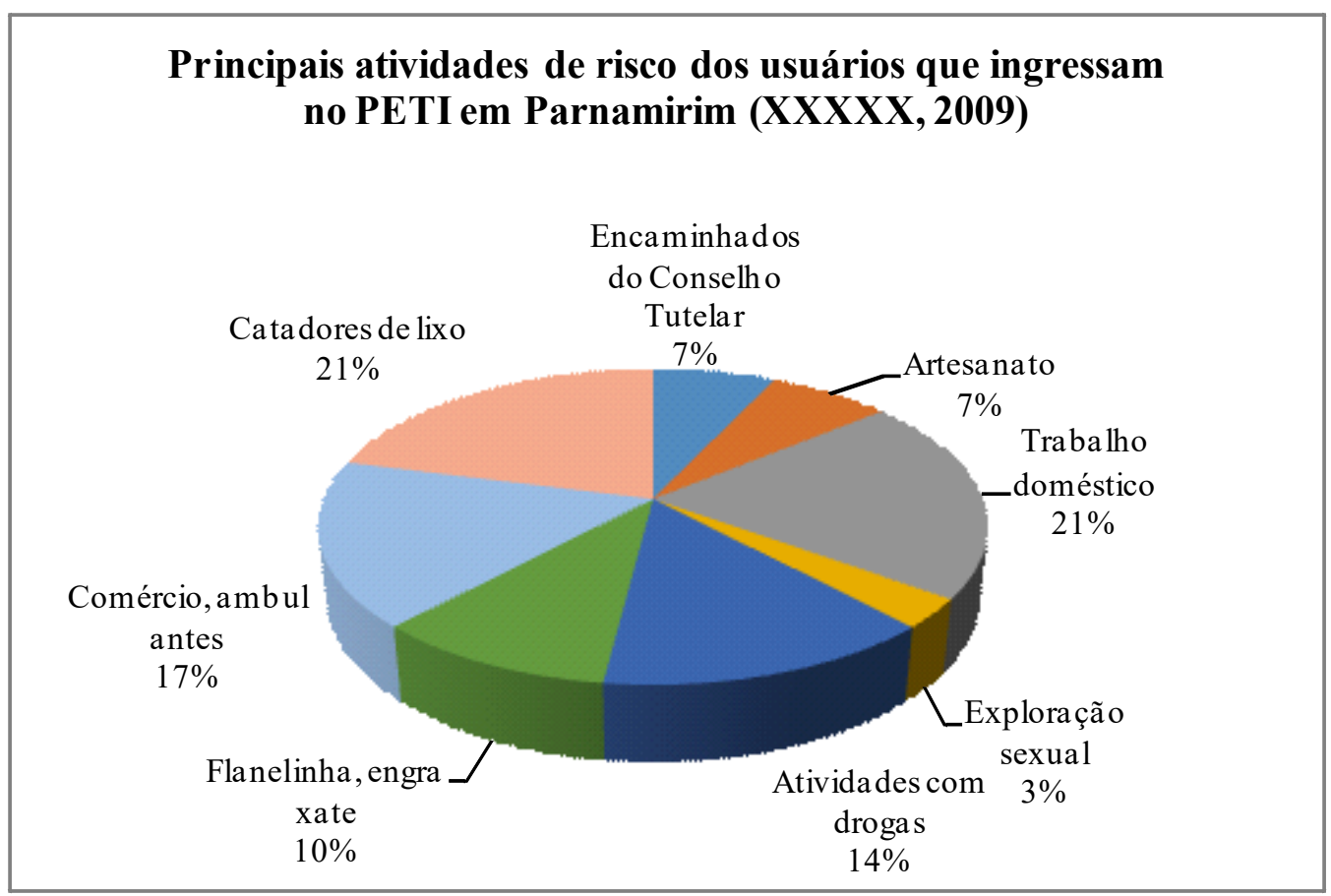

Tabela 1: Atividades de risco dos usuários do PETI - Parnamirim

Fonte: Araujo, 2009.

Como muitas cidades das regiões metropolitanas do Nordeste brasileiro, as atividades relacionadas à reciclagem de lixo e ao trabalho doméstico são tidas como principais formas de trabalho infantil. Nesse sentido, os monitores de música desenvolviam projetos utilizando os conhecimentos que as crianças e adolescentes já possuíam sobre materiais recicláveis. Assim, oficinas de construção de instrumentos musicais com esses materiais eram potencializadas quando os conhecimentos dos usuários eram considerados nas oficinas.

Outra questão sobre o SCFV, pesquisado em 2009, é que as oficinas de construção de instrumentos musicais eram as mais concorridas, pois nelas,

[...] os adolescentes pintavam seus instrumentos, cada um poderia se expressar através da pintura e da música de seus próprios instrumentos, exteriorizando, no processo dialético, a sua realidade social (ARAUJO, 2009, p. 80).

A construção e a manipulação de materiais recicláveis remetiam ao cotidiano dos usuários, havendo uma ressignificação da reciclagem e uma aproximação com as atividades desenvolvidas por seus familiares.

Com isso a elaboração de estratégias do educador musical cria pontos de descontinuidade no pensamento e na relação das crianças com o trabalho. Tais pontos podem acontecer através da música como um catalisador dialógico de vivências. Esses aspectos são concomitantes à aquisição de habilidades musicais, como no caso das oficinas de construção de instrumentos musicais a partir de materiais recicláveis.

\section{Conclusão}

Este trabalho procurou discutir a legislação vigente da Política Nacional de Assistência Social, inter-relacionando o ensino musical ao trabalho social para crianças e adolescentes. A apropriação dessa política, as ações e concepções que regem o trabalho do edu- 
cador musical em programas e projetos assistenciais trazem para a área possibilidades interativas.

Através de processos coletivos, sociais e intersetoriais, o ensino de música pode se constituir uma ferramenta atrativa, resignificando o cotidiano de vulnerabilidade de crianças e adolescentes.

A apropriação desses contextos governamentais possibilita a nós, como área, as seguintes conclusões:

A) é preciso buscar perspectivas para a superação dos riscos sociais, através de ações em redes intersetoriais que utilizam a música como instrumento de intervenção. Os agentes culturais, de saúde, de segurança, professores, mestres da cultura e demais componentes da sociedade podem participar das ações desenvolvidas pelo SCFV e o monitor de música pode ser o articulador desse diálogo. $\mathrm{O}$ fortalecimento de vínculos sociais consiste em ações cotidianas através da convivência no qual a música pode ser o catalisador;

B) esse movimento catalisador musical rompe a dicotomia: trabalho social x qualidade do ensino, uma vez que o trabalho social é intrínseco ao ensino de qualidade. Logo, um trabalho musical sem o compromisso com a aprendizagem pode comprometer a rede socioassistencial, além disso, não garante o direito ao acesso ao bem cultural e ao desenvolvimento cognitivo assegurado pelo Caderno de Orientações Técnicas do SCFV (BRASIL, 2010);

C) para problematizar a aprendizagem musical do SCFV é necessário tomar como ponto de partida as concepções de ensino-aprendizagem que não são estritamente vinculados ao sistema educativo. Tendo a Política Nacional de Assistência Social concepções particulares da utilização do ensino de música, não se pode utilizar os mesmos parâmetros analíticos que se utiliza para se estudar as ações da Política Pública Educacional.

Como desdobramentos e limitações deste trabalho podemos apontar para a problematização da práxis que ocorrem as apropriações supracitadas. Contudo, essa investigação não pode ser contemplada devido à delimitação deste trabalho.

\section{Notas}

1 Local de Acolhimento Institucional voltado para crianças, mulheres ou idosos vítimas de algum tipo de violência, que precisem ser retirados do convívio cotidiano. É no cotidiano e nas relações mais próximas que a violência se faz presente, e, portanto, é dever do Estado proteger tais pessoas vítimas de violência, oferecendo além do abrigo, suporte psicossocial e de reinserção profissional, se for o caso.

2 Instituições que recebem crianças e idosos sem determinação de prévia de tempo. Antigamente chamados de Orfanatos e Asilos, entretanto, como esses nomes possuem uma carga ideológica depreciativa e não só abrigam pessoas órfãs, o nome foi modificado a partir da promulgação do Estatuto da Criança e do Adolescente - ECA, 1992.

3 Entretanto, é necessário salientar que as ações sociais aconteciam no Brasil anteriormente à Constituição de 1988. Como exemplo, as ações de instituições religiosas com o intuito da catequese, instituições filantrópicas, distribuições de cesta básica (que no Brasil ainda acontece com uma perspectiva eleitoreira, e remonta à época do Segundo Império). Além disso, a então primeira dama Darcy Vargas fundou em 1942, a LBA, Legião Brasileira de Assistência, que prestava auxílio social à família dos Pracinhas que lutaram na Segunda Guerra Mundial. Em 1969, é ampliado o público alvo e a instituição passa a se chamar Fundação Legião Brasileira de Assistência, vinculada ao Ministério do Trabalho e Previdência Social. Historicamente a LBA foi presidida pelas primeiras damas brasileiras, tendo seu fim iniciado em 1991 em meio a denúncias de desvio de verbas públicas pela gestão de Rosane Collor. Em 1 de Janeiro de 1995, o recém-empossado presidente Fernando Henrique Cardoso extingue a LBA através de Medida Provisória.

4 Usuário dos serviços, ou simplesmente usuário é o nome dado às pessoas que usam do serviço socioassistencial. Entretanto, é comum ver a expressão ‘aluno’ em alguns trabalhos da área de educação musical (PENNA; BARROS; MELLO, 2012). Contudo, salienta-se que a política pública socioassistencial possui usuários e não alunos.

5 Ao analisar as categorias dos Projetos Sociais, ou seja, dos projetos de atuação social e com demanda social inscritos no Programa Rumos Itaú Cultural: Educação, Cultura e Arte, nos anos de 2005 e 2006, Maria da Glória Gohn classifica-os entre: "programas sociais (de apoio a crianças, jovens/adolescentes, idosos, mulheres etc.), 
prestação de serviços às comunidades (principalmente na área da saúde, educação e habitação), projetos culturais e socioeducativos, apoio econômico (programas de geração de renda) e defesa de bens e patrimônio, material ou imateriais" (GOHN, 2009, p. 36).

\section{Referências}

ARAUJO, Andersonn Henrique. Múltiplos contextos da educação musical: O PETI - Programa de Erradicação do Trabalho Infantil e intenções de trabalho com os saberes musicais dos aprendizes. 2009. Monografia (Graduação em Música) - Escola de Música da Universidade Federal do Rio Grande do Norte, Natal, 2009.

ARAUJO, Andersonn Henrique. Música em projetos socioassistenciais governamentais: práticas e concepções culturais no Serviço de Convivência e Fortalecimento de Vínculos em Natal. 2015. Dissertação (Mestrado em Música) - Escola de Música da Universidade Federal do Rio Grande do Norte, Natal, 2015.

BRASIL. Constituição: Constituição Federativa do Brasil. 1 de outubro de 1988. Brasília: Diário Oficial da União, 1988.

BRASIL. Lei $n^{\circ}$ 8.069, de 13 de julho de 1990. Dispõe sobre o Estatuto da Criança e do Adolescente. Brasília: Diário Oficial da União, 1990.

BRASIL. Lei $n^{\circ}$ 12.435, de 6 de julho de 2011. Altera a Lei $n^{0}$ 8.742, de 7 de dezembro de 1993, que dispõe sobre a organização da Assistência Social. Brasília: Diário Oficial da União, 2011.

BRASIL, Ministério do Desenvolvimento Social e Combate à Fome. Política Nacional de Assistência Social-PNAS/2004, Norma Operacional Básica-NOB/SUAS. Brasília: MDS, 2004.

BRASIL. Orientações Técnicas sobre o Serviço de Convivência e Fortalecimento de Vínculos para Crianças e Adolescentes de 6 a 15 anos: prioridade para crianças e adolescentes integrantes do Programa de Erradicação do Trabalho Infantil. Brasília: MDS, 2010.

BUFALO, Paulo Roberto. Trabalho infantil: políticas públicas e a concepção emancipatória do trabalho. 2008. Dissertação (Mestrado em Educação) - Programa de Pós-Graduação em Educação, Universidade Estadual de Campinas, Campinas, São Paulo, 2008.

CANDIDO, Maria Cristina. Trabalho infantil e as experiências de erradicação. 2005. Dissertação (Mestrado em Educação) - Programa de Pós-Graduação em Educação, Universidade Estadual de Campinas, Campinas, São Paulo, 2005.

FUCCI AMATO, Rita de Cássia. Música e políticas socioculturais: a contribuição do canto coral para a inclusão social. OPUS, Goiânia, v. 15, n. 1, p. 91-109, jun. 2009.

GOHN, Maria da Glória. Educação não-formal, educador(a) social e projetos sociais de inclusão social. META: Avaliação, Rio de Janeiro, v. 1, n. 1, p. 28-43, jan./abr. 2009.

HIKIJI, Rose. A música e o risco: etnografia da performance de crianças participantes de um projeto social de ensino musical. São Paulo: EDUSP, 2006.

MACIEL, Edineiram. Educação musical, projetos sociais e inclusão: um estudo de caso no sertão da Bahia. 2011. Dissertação (Mestrado em Educação e contemporaneidade) - Universidade do Estado da Bahia, Salvador, 2011.

NASCIMENTO, Antônio Dias. Entre música e a escola: um relato de pesquisa em projetos sociais de curta duração. In: SOUZA, Jusamara (Org.). Música, educação e projetos sociais. Porto Alegre: Tomo Editorial, 2014. p. 109-122. 
NASCIMENTO, Sueli do. Reflexões sobre a intersetorialidade entre as políticas públicas. Serviço Social e Sociedade, São Paulo, n. 101, p. 95-120, 2010.

PENNA, Maura. Caminhos para a conquista de espaços para a música na escola: uma discussão em aberto. Revista da ABEM, Porto Alegre, v. 19, p. 57-64, mar. 2008.

. Música(s) e seu ensino. Porto Alegre: Sulina, 2012.

PENNA, Maura; BARROS, Olga; MELLO, Marcel. Educação musical com função social: qualquer prática vale? Revista da ABEM, Londrina, v. 20, n. 27, p. 65-78, 2012.

SARTORI, Elisiane. Família e proteção social: todos sob o mesmo teto. Campinas, SP: Papel Social, 2012.

SANTOS, Marco. Educação musical na escola e nos projetos comunitários e sociais. Revista da ABEM, Porto Alegre, v. 12, p. 31-34, mar. 2005.

SOUZA, Jusamara. Música, educação e projetos sociais. Porto Alegre: Tomo Editorial, 2014

Andersonn Henrique Araújo: Possui graduação em Licenciatura Música pela Universidade Federal do Rio Grande do Norte (2009) e mestrado em Música pela Universidade Federal do Rio Grande do Norte (2015). Atualmente é professor da Universidade do Estado do Rio Grande do Norte. Tem experiência na área de Artes, com ênfase em Educação Musical, atuando principalmente nos seguintes temas: educação musical, programas sociais governamentais, teorias do cotidiano, contextos informais em educação musical e complexidade. 